\title{
Setting up and utilizing Norwegian twin panels
}

\author{
Per Magnus, Jennifer R. Harris and Kristian Tambs \\ Norwegian Institute of Public Health, P.O. Box 4404 Nydalen, 0403 Oslo, Norway \\ Correspondence: Per Magnus, per.magnus@fhi.no
}

\begin{abstract}
In the late 1970s, a Norwegian twin panel was set up. It included all like-sexed twin pairs, born in the period 1915 to 1960 , where both members were alive and had a known address in Norway at the time. The work was initiated through a grant from the National Institutes of Health in the United States. The aim was to estimate maternal effects to understand the causes of variation in traits and diseases that originate in pregnancy. However, the twin panel was also utilized for estimating genetic and environmental effects on a series of phenotypes, for instance lipoproteins, receptors, coagulation factors, cognitive abilities, educational attainment and left-handedness. A short zygosity questionnaire was sent together with the first invitation letter to the twins. Later questionnaires on general health, lifestyles and pregnancy outcomes were sent out. One important finding was that the fetal genotype had much stronger influence on variation in fetal growth than what had been assumed previously. In the early 1990s, the New Norwegian Twin Panel was created, based on information on plural births in the Medical Birth Registry of Norway (MBRN). The panel included both like-sexed and opposite-sexed pairs born in the years 1967 to 1974 . After linking the MBRN to present addresses, using a national identification number, a questionnaire on zygosity, with a few items on health and social background, was sent out. This panel was later expanded to include twins born 1975-1979 and to collect more data on health, well-being and lifestyle factors. The data have been utilized for a series of subprojects, including psychiatric interviews and the collection of DNA samples. Linkage to Norwegian health registries has provided important research opportunities for a variety of phenotypic outcomes.
\end{abstract}

This is an open access article distributed under the Creative Commons Attribution Licence, which permits unrestricted use, distribution, and reproduction in any medium, provided the original work is properly cited.

\section{The Norwegian Twin Panel for the YEARS 1915-1960}

In the nineteenth century, Galton had pointed out that the study of twins could help resolve questions concerning the effects of nature and nurture on human variability. In the 1950s and 1960s, it was well appreciated that the comparison of phenotypic similarity in monozygotic (MZ) and dizygotic (DZ) twins was an important design for estimating the heritability of traits and diseases. Simple estimation methods for continuous and categorical variables were used. In the 1970s, more advanced methods became available with particular input from what was named the Birmingham school of biometrics, led by Kenneth Mather (1). A seminal paper was written by Jinks and Fulker (2). They introduced modelling techniques that included testable assumptions with clear interpretations of genetic and environmental effects. This type of modelling was elaborated by Lindon Eaves and colleagues $(3,4)$. At the same time, general computing programs, such as LISREL, developed by Jøreskog and Sørbom (5), became available. Path analysis was used to create structural equations. The program estimated model parameters and provided likelihood estimates for the fit of the data to the model. The data could be phenotypic correlations, or variance-covariance matrices, for male and female MZ and DZ twins. By contrasting alternative models, the best fitting model was found.

Walter Nance was an American geneticist interested in perinatal epidemiology, working in the Department of Human Genetics at the Medical College of Virginia. Diseases that occur during pregnancy or later in the child can be influenced by the child's genotype, but also by environmental influences. A specific environmental influence is provided by the mother during pregnancy and is partly determined by the maternal genotype, for instance through her body size and metabolism. It had been shown that an understanding of this could be obtained by comparing maternal and paternal half-sibs. If maternal half-sibs, that have had the same maternal genetic influence in utero, are more equal than paternal half-sibs, whose intrauterine environment have been from two unrelated mothers, one can make inferences about the strength of the maternal influence on the child's phenotype, i.e. estimate maternal effects. However, half-sibs, especially in the 1950s and 1960s, originated from split families that may not be very representative of families in general. Walter Nance realized that if two MZ twins marry and both have children with their spouses, these children would be first cousins in a social sense, but would be genetically as closely related as half-sibs, and that by comparing the similarity for phenotypes in offspring of female MZ twins with that of offspring of male MZ twins, he could estimate variance components due to the maternal genotype using stable families. Together with Linda Corey, Nance published the first paper on what he called the MZ half-sib design (6).

To collect data for his new design he looked to the Scandinavian twin registries, and came in contact with Kåre Berg, then professor at the Institute of Medical 
Genetics at the University of Oslo. A grant proposal was written to the National Institutes of Health in the US, and awarded, with a sub-award to the Norwegian institute. Per Magnus was hired in 1977 to design questionnaires and perform the data collection. He was, for the period 1980-82, awarded a PhD scholarship from the Research Council for Science and the Humanities in Norway, based on an application to study pregnancy outcomes using the MZ half-sib design. An American PhD student, Wendy Golden, spent the period of 19781979 in Oslo, participating in the data collection and finishing her dissertation on the maternal effects on early spontaneous abortion $(7,8)$. Her thesis provides many of the data collection procedures.

Professor Berg had made an agreement with Einar Kringlen, a professor of psychiatry at the University of Oslo, who had established a twin registry covering the birth years 1901 to 1930 (later extended to 1895 to 1945) for studies of the genetics of schizophrenia (9). The registry consisted of paper recordings of twin births, originating from records from Statistics Norway. The agreement was that all records for like-sexed twin pairs, for whom present addresses in Norway (thus excluding stillbirths, early deaths and emigrated subjects) could be found through the population registry, should be digitalized, and that the records should be made available for Kringlen's research group. In addition, records that had been assembled at the Institute of Medical Genetics for like-sexed twin pairs for birth years 1946 to 1960, were included.

\section{The process of digitalizing the registry}

A very tedious process of finding current addresses for surviving twins started. It was agreed with Statistics Norway that the Institute could have a copy of the general population registry. The central person registry was available as microfiche information. Present names and addresses of twins were obtained by searching the microfiche for two persons born on the same date with first or last names matching the paper records. Often, nothing more than the day of birth, the mother's name and the place of birth was known. Thus, the task of finding present names for two twins born on the same day to the same mother among all persons in Norway born on the same day was difficult. Female twins had as a rule changed their last name. This process took several years, although questionnaires were sent out for each birth cohort as soon as it was transcribed. In parallel, a computer-based system for storing the personal information and keeping track of all questionnaire correspondence as well as a database was developed by the university's IT personnel. In the 1970s, personal computers and laptops were unknown commodities. Only teletypewriters to a mainframe machine at the university's central IT facility were available. All information in incoming questionnaires had to be punched on the teletypewriters. Lists of addresses were typed out on the same writers, including reminders. At the time, there were no committees of medical ethics and the Data Inspectorate did not exist. All ethical considerations and rules for autonomy and protection of personal information were decided on after discussions at the Institute. Present addresses of 12752 pairs of twins were found.

\section{Zygosity and sampling of biological materials}

A central problem was how to determine the zygosity of the twins. Previously, Cederløf had shown that a simple question of equality, which read: "are you as alike as two drops of water" would single out a large proportion of the MZ pairs (10). DZ pairs almost never responded positively to this question. But among the MZ twins that did not think that they were so alike, other questions had to be used, among them questions of similarity (hair color, eye color, dexterity) and questions on how often other people mixed them up. To validate the questionnaire (Q1) that was created and sent to all twins, it was necessary to determine zygosity based on genetic similarity directly. DNA technology, as used today, was not available. Instead, genetically determined protein variants were analysed. In all, about 20 different protein systems, including some blood groups, were used. If the two members of a pair were equal in all genotypes, they were categorized as $M Z$. The probability that DZ twins should be equal in all these systems could be calculated, and was negligible when 20 markers were used. Blood samples from 207 pairs of like-sexed twins living less than 2 hours' drive from the institute were collected. The sampling of biological materials served many purposes, and was performed in the morning, since determination of lipids required overnight fasting. For a subsample, skin biopsies were taken for receptor studies that required cultivation of fibroblasts. After determination of the genotypes in the 207 pairs, a comparison was made with their responses to the zygosity questionnaire. Using multivariable discriminant analyses, it was shown that about $97 \%$ of the pairs could be assigned to the correct zygosity group, using the answer from only one of the twins in a pair (11). The algorithm from the discriminant analysis could then be applied to all twins. The questionnaire was completed by both members of 9032 pairs and by one of the twins in 2143 pairs. The proportion of pairs where one or both responded, was therefore $87.6 \%$ (11 175/12 752). Among these pairs, about $40 \%$ were estimated to be MZ (11). All twins who responded were subsequently sent three extensive questionnaires (Q2), two of them concerning health and background data for the twin and his or her spouse, and the third concerning pregnancy exposures and outcomes for female twins or the spouses of male twins.

\section{Studies on birth weight}

At the time, the general opinion was that fetal growth was mainly determined by the mother. This was based on animal studies as well as a few family studies (12). Birth weights were reported in Q2, but more precise 
values were obtained by linking the twin panel to the Medical Birth Registry of Norway (13). The registry had, however, started with the birth cohort born in 1967. Thus, only offspring birth weights could be retrieved from the registry. The parental birth weights were only available from Q2. It was found that the father-offspring covariance in birth weight was as high as the mother-offspring covariance, suggesting large effects of the fetal genotype (14). Further support of the importance of fetal genes for explaining the variability in birth weight came from utilizing the MZ half-sibs design, extended to include offspring of DZ twins as well as the inclusion of grandchildren $(15,16)$. Comparison of birth weights of offspring of smokingdiscordant female $\mathrm{MZ}$ twins suggested that smoking was a direct cause of fetal growth restriction, and the results also showed a substantial genetic influence on smoking behavior in pregnancy (17).

\section{Phenotypes based on analyses of biological materials}

Gene-environment interaction: cholesterol and blood groups

Gene by environment interaction is usually studied in situations where direct measurements of genes (or their products) as well as environmental exposures have been made. Monozygotic twins provide a special design since the intra-pair difference is a direct measure of environmentally induced variability (and also includes measurement error). If genetic analyses have been made, the twin pairs can be stratified according to genotype. This novel design was used to show that certain genes in the MNSs and Kidd blood group systems could have a restrictive effect on environmentally caused cholesterol variability (18).

\section{Low density lipoprotein receptor activity}

In the early 1970s, it had been shown by Goldstein and Brown (19) that the basic defect in the autosomal, dominant disease called familiar hypercholesterolemia (FH) was reduced activity in the low density lipoprotein (LDL) receptor. However, it was unknown to which degree variation in receptor activity in subjects without FH was genetically determined. By cultivating fibroblasts collected from $14 \mathrm{MZ}$ and $21 \mathrm{DZ}$ twin pairs, we found larger intra-pair differences in DZ than in $M Z$ pairs, suggesting genetic influence on the variation in this phenotype (20). Interestingly, large intra-pair differences were found in two MZ pairs, both discordant for psoriasis.

\section{Aryl hydrocarbon hydroxylase (AHH) inducibility}

Blood samples from the twins were also used to culture lymphocytes and transform them to lymphoblasts. This opened for estimation of the activity of the aryl hydrocarbon hydroxylase enzyme system, which is important in the metabolism of polyaromatic hydrocarbons $(\mathrm{PAH})$. PAH are environmental carcinogenic contaminants, present in cigarette smoke, and it had been found that $\mathrm{AHH}$ inducibility was higher in subjects with lung cancer. By analyzing data from $28 \mathrm{MZ}$ and $19 \mathrm{DZ}$ pairs we found suggestive evidence that $\mathrm{AHH}$ inducibility was mainly influenced by genetic factors (21).

\section{Coagulation factors VIII and IX}

The influence of genes on the levels of coagulation factors in a representative population sample had not previously been examined. Using $74 \mathrm{MZ}$ and $84 \mathrm{DZ}$ pairs, we could show that there was no genetic effect on the variability of factor IX, while the heritability for factor VIII was estimated to about $60 \%$. An important finding was that $30 \%$ of the genetic variance could be attributed to the ABO blood group system (22).

\section{Sister chromatide exchanges (SCE)}

In the mitotic metaphase, exchange of DNA between sister chromatids are easily observable. The amount of exchange has been found to increase after exposure to mutagens and carcinogens, and the examination of SCE is used as a measure of exposure to mutagenic factors in the environment. However, little was known about the degree to which genetic factors influenced the level of SCE. Using cultured fibroblasts from 11 $\mathrm{MZ}$ and $10 \mathrm{DZ}$ pairs, we showed that there was little difference between male and female subjects in SCE level, while the level was higher in older subjects. The within variance was, however, quite similar for MZ and DZ pairs, suggesting little influence of genetic factors (23).

\section{Transcobalamin}

Transcobalamin II (TC II) is the major protein that carries vitamin B12 (cobalamin) to the tissues. The levels of unsaturated TC II and cobalamin vary widely in the population, and little was known about the determining factors behind this variability. We found, by analyzing the plasma levels in $96 \mathrm{MZ}$ and $106 \mathrm{DZ}$ twin pairs, that the variance in UTC II was mainly genetically determined (24).

\section{Other phenotypes studied in the 1915-1960 twin panel} IQ

The Wechsler Adult Intelligence Scale (WAIS) test consists of 11 subtests, each measuring specific cognitive abilities. A sample of $40 \mathrm{MZ}$ and $40 \mathrm{DZ}$ pairs, living in or close to Oslo, were tested. The heritability estimates for total IQ and for the components verbal ability, spatial ability and "freedom from distractibility" were between 0.6 and 0.8 (25-27). More importantly, this study was one of the first to show that the major part of genetic variability in the various types of specific abilities stems from the same sets of genes. Further, the high correlation between such specific abilities, having led to an assumption of an underlying general factor, "G-factor" for intelligence, appeared to be almost entirely due to genetic covariance (26). That is, the existence of the G-factor has a biological, rather than a social basis.

Parts of the male twin panel were linked to cognitive ability (IQ) scores from the Norwegian army with valid data from around $90 \%$ of the male Norwegian 
population. There were valid IQ data in 1082 complete pairs, a very big sample for its time. This material, giving more precise results than the small WAIS sample, basically confirmed the results from the small sample regarding the G-factor, showing that the correlation between three types of ability was almost only due to the effect of a common set of genes (28). The heritability for sub-scores was estimated at around 0.4 in a cohort born 1931-35 and around 0.7 in three cohorts born between 1944 and 1960. The effect of environmental effects common to the co-twins was 0.45 in the oldest cohort but only around 0.1-0.2 for the younger cohorts $(29,30)$. The results suggest that higher degree of social equality after World War 2 than in the 1930s was accompanied by increasing importance of genetic variability compared to environmental variability between families. An implication of these results is that there is no such thing as the best or most correct estimate of IQ heritability, it depends on environmental circumstances.

The results from the same study showed a strong correlation between occupational status, educational attainment, and intelligence. Most of this correlation appeared to be due to environmental family factors common to the three variables for twins born 1931-35. In twins born later most of the correlation was due to common genes, but some of the correlation could still be accounted for by family environment (30).

The participation rate of twin studies of IQ and highly related variables, like self-reported educational attainment, is usually far from perfect. Results from such studies have been criticized for being subject to recruitment bias. Some of the twins with valid IQ data from the army had responded to the second questionnaire from the Institute of Medical Genetics, with information about education, income and other demographic information, others had not responded. The heritability and effect of family environment for IQ was estimated separately for the questionnaire responders and for the non-responders. The results were almost identical in the two groups, suggesting no large recruitment bias for IQ related variables (31).

We organized a "Saturday twin family clinic" to perform in-depth analyses of a number of psychological variables in $\mathrm{MZ}$ twins and their families, altogether 1150 subjects living close to the Institute of Medical Genetics in Oslo. Invitations were accepted by around $50 \%$. A study on partner similarity for IQ used data from this material. A moderate or strong spouse resemblance can be observed for many traits and characteristics. The similarity is usually assumed either to reflect assortative mating, in which the people actively tend to select partners similar to themselves, or social homogamy, that is, people more often mate within groups differing for specific characteristics than across groups. An example of the latter is that highly educated people mate more often than by chance, probably because they stick together during the period of education and later. One prediction from assortative mating is that the correlation between spouses is clearly higher than between MZ twins and their co-twins' spouses. This, in turn, is expected to be higher than between each of the co-twins' spouses. The predictions from social homogamy are much more similar correlations between spouses and siblings-in-law. Structural equation model testing showed that a model of social homogamy fitted best with the correlation structure, and that at least a substantial part of spouse resemblance for IQ is due to social homogamy rather than assortative mating (32).

\section{Educational attainment}

Using the same kind of reasoning as for IQ, a study comparing twins born before and after the Second World War were compared using educational attainment as reported by the twins in the second questionnaire. Using responses from 4608 pairs, it was found that the variance attributable to common environment had declined for males, but not for females when postwar generations were compared to pre-war generations (33). The same data set was used to study assortative mating for educational attainment (34).

\section{Left-handedness}

A separate questionnaire was mailed to the twin panel in one Norwegian county and returned by 976 twins ( $80 \%$ participation rate). The questionnaire included questions on the twins' own handedness and on their parents', siblings', spouses' and children's handedness. The combination of the observed correlations in handedness between various types of relatives did not show substantial genetic influence. Nor did they show much evidence of familial aggregation due to common environment, but the correlation pattern was consistent with a moderate maternal environmental effect (35).

\section{Personality and anxiety}

Model testing of family correlation data on MZ twins and their families from the Saturday clinic showed a heritability of $0.53,0.36$, and 0.39 for the personality traits extraversion, neuroticism, and psychoticism, respectively. There was evidence of non-additive genetic effect (genetic dominance) and no evidence of sex specific effects or effect of family environment (36). The results are highly consistent with those from ordinary twin designs and contribute to confirm them. The same type of analyses of Type A personality (stress-related, once assumed to predict cardiovascular illness) showed heritability estimates of 0.33 for men and 0.39 for women. The estimates varied from 0.13 to 0.52 for various components of Type A and were generally somewhat higher for women than for men. Again there was no evidence of effects of family environment (37). The participants also reported different types of phobic fear. The categories were Situational fears, (e.g. swimming alone, darkness, flying), Illness-injury fears (e.g. car accident, death of loved ones, insanity), Social fears (e.g. committing errors, being misunderstood, looking silly), and Fear of small animals (e.g. snakes, rats and mice, spiders). The heritability estimates were 
$0.47,0.25,0.22$, and 0.32 , respectively, and effects of family environment were estimated at zero. Intercorrelations ranging from 0.22 to 0.26 between the four types of fear were explained both by common genetic factors and by common environmental factors, apparently mostly by the latter (38).

\section{Common eye diseases}

Using the data from Q2, information on six common eye disorders (nearsightedness, farsightedness, astigmatism, squint, cataracts and glaucoma) for the twins, their spouses and offspring were analyzed. For the three first-named disorders, heritability estimates ranged from $62 \%$ for astigmatism to $92 \%$ for nearsightedness. The spousal correlations were high, 0.28 for nearsightedness and 0.48 for farsightedness. This non-random mating increases the incidence of these disorders in the population quite substantially (39). It was estimated that $31 \%$ of all cases of nearsightedness and $62 \%$ of cases of farsightedness is directly attributable to the mating structure of the population.

\section{Blood pressure}

As part of the collection of biological materials from the twin pairs, blood pressures were taken. Systolic and diastolic pressure readings from 200 pairs were subjected to genetic analyses which showed that the heritability was $56 \%$ for systolic and $71 \%$ for diastolic blood pressure (40). The zygosity information on twins who participated in the Nord-Trøndelag Health Study (HUNT) was used to analyze twin data together with nuclear family data. The heritability estimated from these data was $51 \%$ for systolic and $35 \%$ for diastolic blood pressure. There was no effect of environmental factors shared by all family members, but there was a small environmental effect shared only by siblings and twins (41).

Some other phenotypes examined with HUNT and twin data.

Using the same combination of HUNT and twin data, heritability was estimated at 0.40 for body mass index (42), 0.80 for body height (43) and 0.19 for symptoms of anxiety and depression (44). In general, fitting our statistical models judged to be the most realistic (but not the only possible choice) to the twin and nuclear family data gave somewhat lower heritability estimates than expected from classical twin studies.

\section{The NeW Norwegian Twin Panel for THE BIRTH YEARS 1967-1979}

In 1992, a new Norwegian twin panel was established at the Norwegian Institute of Public Health (NIPH) through a research grant from the Norwegian Research Council awarded to Jennifer Harris. Working together with Per Magnus and Kristian Tambs, the vision was to develop a broad, collaborative and sustainable program of twin research spanning physical and mental health outcomes, which would catalyse multiple subprojects that could conduct deeper phenotyping in concert with the interests of the associated researchers. The original project established a population-based cohort of twins born 1967-1974 to study sex differences in genetic and environmental influences on a broad range of health and developmental outcomes. Twin births were identified through the Medical Birth Registry of Norway (MBR) which contains an item specifying whether there was a plural birth. A short mail-out questionnaire was sent to 7992 twins in 3996 pairs who were at least 18 years old in 1992. Responses were received from 5864 twins $(73 \%)$ and included 2570 pairs and 724 single responders (45). The questionnaire included items that a previous study found were reliable for classifying zygosity (11) plus questions about height, weight, health history with ages of onset, self-perceived health, psychological well-being, lifestyle behaviors, co-twin contact measures and demographic information. Through linkage to the MBR, standardized information was also obtained about the delivery, birth order, gestational age, birth weight and length, ICD-8 coded measures of maternal health before and during pregnancy, circumstances, interventions and complications related to the delivery, status of the newborn, and demographic information about the parents.

A new grant funded through the Norwegian Research Council permitted extension and expansion of the NIPH twin panel. In 1998 a second, more extensive questionnaire (Q2) was sent to the cohorts who received Q1 (twins born 1967-1974), plus to five new birth cohorts (twins born 1975-1979) (46). In addition to repeating all the questions from the 1992 study, the follow-up questionnaire was more comprehensive regarding the measurement of physical health, mental health, health-related behaviors and exposures. Importantly, through coordination with researchers interested in developing projects focused on specific health outcomes, Q2 also included a number of items for screening.

Altogether, more than 9500 twins (including 4178 responding pairs) participated in at least one of these two questionnaire studies. The longitudinal sample responding to both Q1 and Q2 included 4430 twins and 1725 pairs. The Q1 and Q2 data were well curated and developed as a research resource. Numerous scientific manuscripts have been published and several doctoral dissertations, book chapters and scientific presentations are based on these data. This body of research is too large to summarize here, it spans a wide range of health-related outcomes including, for example, body composition $(45,47)$, asthma (48-50), psoriasis $(51,52)$, irritable bowel syndrome $(53,54)$ and inflammatory bowel disease (55), diverse measures of well-being $(56-58)$, mental health $(59,60)$ and eating disorders (61-63), exercise behaviors $(64,65)$, pain sensitivity $(66,67)$, epilepsy $(68)$, ear-nose-throat problems (69-74), birth weight (75), plus ethical issues specific to twin studies (76). Collectively, these findings have provided important insights into the role of gene- 
tic and environmental influences on this wide array of outcomes, and have helped elucidate the nature of relationships between comorbidities and between risk factors and health outcomes.

This NIPH twin program of research has attracted many scientists and been the basis for developing a number of spin-off projects which received funding for further data collection and analyses, including epigenetics and autoimmune research $(77,78)$, lung function (50) and panic disorder (79). One of these spin-off projects, a large longitudinal study on mental health (80-84), also includes a number of sub projects, among others one on alcohol consumption (85), and another on sick leave and disability pensioning (86). In addition, we were partners in the EU funded GenomEUtwin 'Genome-wide analyses of European twin cohorts to identify genes in common diseases' (87). GenomEUtwin was one of the early EU harmonization projects that worked to establish a data sharing and analysis platform for integrating and analysing twin data across eight countries.

In 2009, the Norwegian Twin Registry was established (88) and the twin cohorts comprising the NIPH panel became integrated into the NTR along with the NIPH Q1 and Q2 data. Through the NTR there are additional opportunities for leveraging and developing the data. For example, we participate in several international consortia where the NIPH data are enhanced through linkage to national health registries and the sample sizes have been augmented by adding data from other cohorts born before the NIPH panel. This is illustrated by the Nordic Twin Cancer Consortium
(NorTwinCan) which involves researchers from the Nordic countries together with cancer epidemiologists at Harvard University in the USA. NorTwinCan has established a unique database comprised of nationwide Nordic Registries from Norway, Denmark, Finland and Sweden (http://nortwincan.org/). It includes data on more than 300000 twins which have been linked with information on cancer incidence and mortality and includes decades of follow-up (89-91). Due to the large sample and long follow-up time, NorTwinCan is able to provide more accurate estimates of genetic and environmental influences on the liability to develop different types of cancer (including some of the rarer cancers), while taking into consideration the competing risks of death and data censoring. New findings from NorTwinCan reveal excess familial risk for the development of cancer and also showed that when both members of a pair developed cancer, it was more common that each twin was diagnosed with a different malignancy, indicating familial aggregation across different cancer types (89). Other ongoing large consortia study that draw heavily on the NIPH panel data include the COllaborative project of Development of Anthropometrical measures in Twins (CODATwins) that currently includes 54 twin cohorts $(92,93)$ and the Discordant Twin Consortium (DISCOTWIN) focused on metabolic disorders (94). In the age of Big Data the value of these consortia is growing and we are also exploring possibilities of integrating the twin cohorts across Europe into the pan-European Biobanking and Biomolecular Research Infrastructure (http://bbmrieric.eu).

\section{REFERENCES}

1. Mather K, Jinks JL. Biometrical Genetics: The study of continuous variation. Cornell University Press, 1971.

2. Jinks JL, Fulker DW. Comparison of the biometrical genetical, MAVA, and classical approaches to the analysis of human behavior. Psychol Bull 1970;73:311-49.

3. Eaves LJ. Inferring the causes of human variation. J R Statist Soc 1977; 140:324-55.

4. Eaves LJ, Last KA, Young PA, Martin NG. Model-fitting approaches to the analysis of human behavior. Heredity 1978;41:249-320.

5. Jøreskog KD, Sørbom D. LISREL, analysis of linear structural relationships by the method of maximum likelihood. Version IV. Chicago, International Educational Services.

6. Nance WE, Corey LA. Genetic models for the analysis of data from the families of identical twins. Genetics 1976;83:811-26.

7. Golden WL, Winter RM, Eaves L, et al. The analysis of spontaneous abortion using a new half-sib model for qualitative traits. Prog Clin Biol Res 1981;69A:197-202.

8. Golden WL. Reproductive histories in a Norwegian twin population: evaluation of the maternal effect in early spontaneous abortion. PhD thesis submitted to the Virginia Commonwealth University, 1980.

9. Kringlen E. Schizophrenia in male monozygotic twins. Acta Psychiatr Scand 1964;40(Suppl 178)1-76.

10. Cederløf R, Friberg L, Jonsson E, Kaij L. Studies on similarity diagnosis in twins with the aid of a mailed questionnaire. Acta Genet Statist Med 1961;11:338-62.

11. Magnus P, Berg K, Nance WE. Predicting zygosity in Norwegian twins born 1915-1960. Clin Genet 1983;24: $103-12$.

12. Robson EB. Birth weight in cousins. Ann Hum Genet 1955;19:262-8.

13. Irgens LM. The Medical Birth Registry of Norway. Epidemiological research and surveillance throughout 30 years. Acta Obstet Gynecol Scand 2000;79:435-9. 
14. Magnus P, Berg K, Bjerkedal T, Nance WE. Parental determinants of birth weight. Clin Genet 1984;26:397405.

15. Magnus P. Causes of variation in birth weight. A study of offspring of twins. Clin Genet 1984;25:15-24.

16. Magnus P. Further evidence for a significant effect of fetal genes on variation in birth weight. Clin Genet 1984;26:289-96.

17. Magnus P, Berg K, Bjerkedal T, Nance WE. The heritability of smoking in pregnancy and the birth weights of offspring of smoking-discordant twins. Scand J Soc Med 1985;13:29-34.

18. Magnus P, Berg K, Børresen A-L, Nance WE. Apparent influence of marker genotypes on variation in serum cholesterol in monozygous twins. Clin Genet 1981;19:67-70.

19. Goldstein JL, Brown MS. Binding and degradation of low density lipoprotein by cultured human fibroblasts: Comparison of cells from a normal subject and from a patient with homozygous familial hypercholesterolemia. J Biol Chem 1974;249:5153-62.

20. Magnus P, Maartmann-Moe K, Golden W, et al. Genetics of the low density lipoprotein receptor: II. Genetic control of variation in cell membrane low density lipoprotein receptor activity in cultured fibroblasts. Clin Genet 1981;20:104-12.

21. Børresen A-L, Berg K, Magnus P. A twin study of aryl hydrocarbon hydoxylase (AHH) inducibility in cultured lymphocytes. Clin Genet 1981;19:281-9.

22. Ørstavik KH, Magnus P, Reisner H, et al. Factor VIII and factor IX in a twin population. Evidence for a major effect of ABO locus on factor VIII level. Am J Hum Genet 1985;37:89-101.

23. Waksvik H, Magnus P, Berg K. Effects of age, sex and genes on sister chromatide exchange. Clin Genet 1981;20:449-54.

24. Magnus P, Magnus EM, Berg K. Evidence for genetic effects on variation in plasma unsaturated transcobalamin II and cobalamin (vitamin B12). Scand J Haematol 1984;33:180-86.

25. Tambs K, Sundet JM, Magnus P. Heritability analysis of the WAIS subtests. A study of twins. Intelligence 1984;8:283-93.

26. Tambs K, Sundet JM, Magnus P. Genetic and environmental contributions to the covariation between the Wechsler adult intelligence scale (WAIS) subtests: A study of twins. Behav Genet 1986;16:475-91.

27. Sundet JM, Tambs K, Magnus P. Heritability analysis as a means of analysing the effects of social changes on psychological variables. An empirical study of IQ scores. Psychiatr Soc Sci 1981;1:241-8.

28. Tambs K, Sundet JM, Magnus P. Genetic and environmental effects on the covariance structure of the Norwegian army ability tests. A study of twins. Person Indiv Diff 1988;9:791-9.

29. Sundet JM, Tambs K, Magnus P, Berg K. On the question of secular trends in the heritability of intelligence test scores: A study of Norwegian twins. Intelligence 1988;12:47-60.

30. Tambs K, Sundet JM, Magnus P, Berg K. Genetic and environmental contributions to the covariance between occupational status, educational attainment, and IQ: A study of twins. Behav Genet 1989;19:209-22.

31. Tambs K, Sundet JM, Magnus P, Berg K. No recruitment bias for questionnaire data related to IQ in classical twin studies. Person Indiv Diff 1989;10:269-71.

32. Tambs K, Sundet JM, Berg K. Correlations between identical twins and their spouses suggest social homogamy for intelligence in Norway. Person Indiv Diff 1993;14:279-81

33. Heath AC, Berg K, Eaves LJ, et al. Education policy and the heritability of educational attainment. Nature 1985;314:734-6.

34. Heath AC, Berg K, Eaves LJ, et al. No decline in assortative mating for educational level. Behav Genet 1985;15:349-69.

35. Tambs K, Magnus P. Berg K. Left handedness in twin families. Support of an environmental hypothesis. Percept Mot Skills 1987;64:155-70.

36. Tambs K, Sundet JM, Eaves L, Berg K. Pedigree analysis of EPQ scores in MZ twin families. Behav Genet 1991;21:369-82.

37. Tambs K, Sundet JM, Eaves L, et al. Genetic and environmental effects on Type A scores in MZ twin families. Behavior Genetics 1992;22;499-513.

38. Sundet JM, Skre I, Okkenhaug JJ, Tambs K. Genetic and environmental causes of the interrelationships between self-reported fears. A study of a non-clinical sample of Norwegian identical twins and their families. Scand J Psychol 2003;44:97-106.

39. Nance WE, Corey LA, Boughman JA, et al. Distribution of common eye diseases in the families of Norwegian twins. Birth Defects Orig Artic Ser 1982;18:669-78.

40. Heiberg A, Magnus P, Berg K, Nance WE. Blood pressure in Norwegian twins. In: Twin Research 3, epidemiological and clinical studies, Alan R Liss Inc, New York, 1981: 163-6.

41. Tambs K, Moum T, Holmen J, et al. Genetic and environmental effects on blood pressure in a Norwegian sample. Genet Epidemiol 1992;9:11-26. 
42. Tambs K, Moum T, Eaves LJ, et al. Genetic and environmental contributions to the variance of body mass index in a Norwegian sample of first and second degree relatives. Am J Hum Biol 1991;3:257-67.

43. Tambs K, Moum T, Eaves LJ, et al. Genetic and environmental contributions to the variance of body height in a sample of first and second degree relatives. Am J Phys Anthropol 1992; 88:285-94.

44. Tambs K, Moum T. Low genetic effect and age specific family effect for symptoms of anxiety and depression in nuclear families, halfsibs and twins. J Affect Disord 1993;27:183-195.

45. Harris JR, Tambs K, Magnus P. Sex-specific effects for body mass index in the new Norwegian twin panel. Genet Epidemiol 1995;12:251-65.

46. Harris JR, Magnus P, Tambs K. The Norwegian Institute of Public Health Twin Panel: a description of the sample and program of research. Twin Res 2002;5:415-23.

47. Schousboe K, Willemsen G, Kyvik KO, et al. Sex differences in heritability of BMI: a comparative study of results from twin studies in eight countries. Twin Res 2003;6:409-21.

48. Harris JR, Magnus P, Samuelsen SO, et al. No evidence for effects of family environment on asthma. A retrospective study of Norwegian twins. Am J Respir Crit Care Med 1997;156:43-9.

49. Nystad W, Røysamb E, Magnus P, et al. A comparison of genetic and environmental variance structures for asthma, hay fever and eczema with symptoms of the same diseases: a study of Norwegian twins. Int $J$ Epidemiol 2005;34:1302-9.

50. Lund MB, Kongerud J, Nystad W, et al. Genetic and environmental effects on exhaled nitric oxide and airway responsiveness in a population-based sample of twins. Eur Respir J 2007;29:292-8.

51. Olsen AO, Grjibovski A, Magnus P, et al. Psoriasis in Norway as observed in a population-based Norwegian twin panel. Br J Dermatol 2005;153:346-51.

52. Grjibovski AM, Olsen AO, Magnus P, et al. Psoriasis in Norwegian twins: contribution of genetic and environmental effects. J Eur Acad Dermatol Venereol 2007;21:1337-43.

53. Bengtson MB, Ronning T, Vatn MH, et al. Irritable bowel syndrome in twins: genes and environment. Gut 2006;55:1754-9.

54. Bengtson MB, Aamodt G, Vatn MH, et al. Co-occurrence of IBS and symptoms of anxiety or depression, among Norwegian twins, is influenced by both heredity and intrauterine growth. BMC Gastroenterol 2015;15:9.

55. Bengtson MB, Aamodt G, Vatn MH, et al. Concordance for IBD among twins compared to ordinary siblings-a Norwegian population-based study. J Crohns Colitis 2010;4:312-8.

56. Nes RB, Røysamb E, Tambs K, et al. Subjective well-being: genetic and environmental contributions to stability and change. Psychol Med 2006;36:1033-42.

57. Nes RB, Røysamb E, Harris JR, et al. Mates and marriage matter: genetic and environmental influences on subjective wellbeing across marital status. Twin Res Hum Genet 2010;13:312-21.

58. Røysamb E, Tambs K, Reichborn-Kjennerud T, et al. Happiness and health: environmental and genetic contributions to the relationship between subjective well-being, perceived health, and somatic illness. J Pers Soc Psychol 2003;85:1136-46.

59. Tambs K, Harris JR, Magnus P. Sex-specific causal factors and effects of common environment for symptoms of anxiety and depression in twins. Behav Genet 1995;25:33-44.

60. Tambs K, Czajkowsky N, Røysamb E, et al. Structure of genetic and environmental risk factors for dimensional representations of DSM-IV anxiety disorders. Br J Psychiatry 2009;195:301-7.

61. Reichborn-Kjennerud T, Bulik CM, Kendler KS, et al. Gender differences in binge-eating: a population-based twin study. Acta Psychiatr Scand 2003;108:196-202.

62. Reichborn-Kjennerud T, Bulik CM, Kendler KS, et al. Undue influence of weight on self-evaluation: a population-based twin study of gender differences. Int J Eat Disord 2004;35:123-32; discussion 33-5.

63. Reichborn-Kjennerud T, Bulik CM, Sullivan PF, et al. Psychiatric and medical symptoms in binge eating in the absence of compensatory behaviors. Obes Res 2004;12:1445-54.

64. Stubbe JH, Boomsma DI, Vink JM, et al. Genetic influences on exercise participation in 37,051 twin pairs from seven countries. PLoS One 2006;1:e22.

65. Vink JM, Boomsma DI, Medland SE, et al. Variance components models for physical activity with age as modifier: a comparative twin study in seven countries. Twin Res Hum Genet 2011;14:25-34.

66. Nielsen CS, Price DD, Vassend O, et al. Characterizing individual differences in heat-pain sensitivity. Pain 2005;119:65-74.

67. Nielsen CS, Stubhaug A, Price DD, et al. Individual differences in pain sensitivity: genetic and environmental contributions. Pain 2008;136:21-9.

68. Kjeldsen MJ, Corey LA, Solaas MH, et al. Genetic factors in seizures: a population-based study of 47,626 US, Norwegian and Danish twin pairs. Twin Res Hum Genet 2005;8:138-47.

69. Kværner KJ, Tambs K, Harris JR, et al. The relationship between otitis media and intrauterine growth: a cotwin control study. Int J Pediatr Otorhinolaryngol 1996;37:217-25. 
70. Kværner KJ, Tambs K, Harris JR, et al. Distribution and heritability of recurrent ear infections. Ann Otol Rhinol Laryngol 1997;106:624-32.

71. Kværner KJ, Tambs K, Harris JR, et al. Otitis media: relationship to tonsillitis, sinusitis and atopic diseases. Int J Pediatr Otorhinolaryngol 1996;35:127-41.

72. Kvestad E, Kværner KJ, Røysamb E, et al. Heritability of recurrent tonsillitis. Arch Otolaryngol Head Neck Surg 2005;131:383-7.

73. Kvestad E, Kværner KJ, Røysamb E, et al. Otitis media: genetic factors and sex differences. Twin Res 2004; 7:239-44

74. Kvestad E, Kværner KJ, Røysamb E, et al. The reliability of self-reported childhood otitis media by adults. Int $J$ Pediatr Otorhinolaryngol 2006;70:597-602.

75. Glinianaia SV, Magnus P, Harris JR, et al. Is there a consequence for fetal growth of having an unlike-sexed cohabitant in utero? Int J Epidemiol 1998;27:657-9.

76. Harris JR, Willemsen G, Aitlahti T, et al. Ethical issues and GenomEUtwin. Twin Res 2003;6:455-63.

77. Gervin K, Hammero M, Akselsen HE, et al. Extensive variation and low heritability of DNA methylation identified in a twin study. Genome Res 2011;21:1813-21.

78. Gervin K, Vigeland MD, Mattingsdal M, et al. DNA methylation and gene expression changes in monozygotic twins discordant for psoriasis: identification of epigenetically dysregulated genes. PLoS Genet 2012;8: e1002454.

79. Battaglia M, Ogliari A, Harris J, et al. A genetic study of the acute anxious response to carbon dioxide stimulation in man. J Psychiatr Res 2007;41:906-17.

80. Tambs K, Rønning T, Prescott CA, et al. The Norwegian Institute of Public Health twin study of mental health: examining recruitment and attrition bias. Twin Res Hum Genet 2009;12:158-68.

81. Kendler KS, Aggen SH, Neale MC, et al. A longitudinal twin study of cluster A personality disorders. Psychol Med 2015;45:1531-8.

82. Kendler KS, Aggen SH, Czajkowski NO, et al. The structure of genetic and environmental risk factors for DSM-IV personality disorders. A multivariate twin study. Arch Gen Psychiatry 2008;65:1438-46.

83. Reichborn-Kjennerud T, Ystrøm E, Neale MC, et al. The structure of genetic and environmental risk factors for symptoms of DSM-IV borderline personality disorder. JAMA Psychiatry 2013;70:1206-14.

84. Ørstavik RE, Reichborn-Kjennerud T, Tambs K, et al. The relationship between depressive personality disorder and major depressive disorder: A population-based twin study. Am J Psychiatry 2007;164:1866-72.

85. Ystrøm E, Kendler KS, Reichborn-Kjennerud T. Early age of alcohol initiation is not the cause of alcohol use disorders in adulthood, but is a major indicator of genetic risk. A population-based twin study. Addiction 2014;109:1824-32.

86. Gjerde LC, Røysamb E, Czajkowski NO, et al. Personality disorders and long-term sick leave: A populationbased study of young adult Norwegian twins. Twin Res Hum Genet 2014;17:1-9.

87. Peltonen L, on behalf of the GenomEUtwin. GenomEUtwin: a strategy to identify genetic influences on health and disease. Twin Res 2003;6:354-60.

88. Nilsen TS, Brandt I, Magnus P, et al. The Norwegian Twin Registry. Twin Res Hum Genet 2012;15:775-80.

89. Mucci LA, Hjelmborg JB, Harris JR, et al. Familial risk and heritability of cancer among twins in Nordic countries. JAMA 2016;315:68-76.

90. Hjelmborg JB, Scheike T, Holst K, et al. The heritability of prostate cancer in the Nordic Twin Study of Cancer. Cancer Epidemiol Biomarkers Prev 2014;23:2303-10.

91. Moller S, Mucci LA, Harris JR, et al. The heritability of breast cancer among women in the Nordic Twin Study of Cancer. Cancer Epidemiol Biomarkers Prev 2016;25:145-50.

92. Silventoinen K, Jelenkovic A, Sund R, et al. The CODATwins Project: The cohort description of collaborative project of development of anthropometrical measures in twins to study macro-environmental variation in genetic and environmental effects on anthropometric traits. Twin Res Hum Genet 2015;18:348-60.

93. Jelenkovic A, Yokoyama Y, Sund R, et al. Zygosity differences in height and body mass index of twins from infancy to old age: A study of the CODATwins Project. Twin Res Hum Genet 2015;18:557-70.

94. Willemsen G, Ward KJ, Bell CG, et al. The concordance and heritability of type 2 diabetes in 34,166 twin pairs from international twin registers: The Discordant Twin (DISCOTWIN) Consortium. Twin Res Hum Genet 2015;18:762-71. 